STUDI

FRANCESI

\section{Studi Francesi}

Rivista quadrimestrale fondata da Franco Simone

152 (니 | II) | 2007

Varia

\title{
Martijn Rus, L'Économie de la digression dans la littérature française de la fin du Moyen-Âge et de la Renaissance
}

\section{Paola Cifarelli}

\section{(2) OpenEdition \\ Journals}

\section{Edizione digitale}

URL: http://journals.openedition.org/studifrancesi/9790

DOI: $10.4000 /$ studifrancesi.9790

ISSN: 2421-5856

\section{Editore}

Rosenberg \& Sellier

\section{Edizione cartacea}

Data di pubblicazione: 1 octobre 2007

Paginazione: 419

ISSN: 0039-2944

\section{Notizia bibliografica digitale}

Paola Cifarelli, «Martijn Rus, L'Économie de la digression dans la littérature française de la fin du MoyenÂge et de la Renaissance», Studi Francesi [Online], 152 (LI | II) | 2007, online dal 30 novembre 2015, consultato il 09 janvier 2021. URL: http://journals.openedition.org/studifrancesi/9790 ; DOI: https:// doi.org/10.4000/studifrancesi.9790

Questo documento è stato generato automaticamente il 9 janvier 2021.

\section{cc) $($ ) $\ominus$}

Studi Francesi è distribuita con Licenza Creative Commons Attribuzione - Non commerciale - Non opere derivate 4.0 Internazionale. 


\title{
Martijn Rus, L'Économie de la digression dans la littérature française de la fin du Moyen-Âge et de la Renaissance
}

\author{
Paola Cifarelli
}

\section{NOTIZIA}

MARTIJN RUS, L'Économie de la digression dans la littérature française de la fin du Moyen-Âge et de la Renaissance, «Les Lettres Romanes», LIX, 1-2, 2005, pp. 17-34.

Dopo aver fornito una definizione del termine 'digression', inteso qui come 'interruption, moment d'arrêt dans le récit', e averne proposto una classificazione sulla base dei rapporti con il testo nel quale è inserito, l'A. propone di identificare l'origine della fortuna che ebbe questo modo narrativo alla fine del Medioevo nel linguaggio giuridico e amministrativo, il quale fornisce un modello utilizzato con finalità diverse nei vari generi narrativi. Sono qui presi in considerazione il genere storico, che interessa più particolarmente questa rassegna, l'opera di Rabelais e quella di Montaigne. 